Arthritis Rheumatol, 2018, 70 (Suppl 9): 2018 ACR/ARHP Annual Meeting Abstract Supplement.
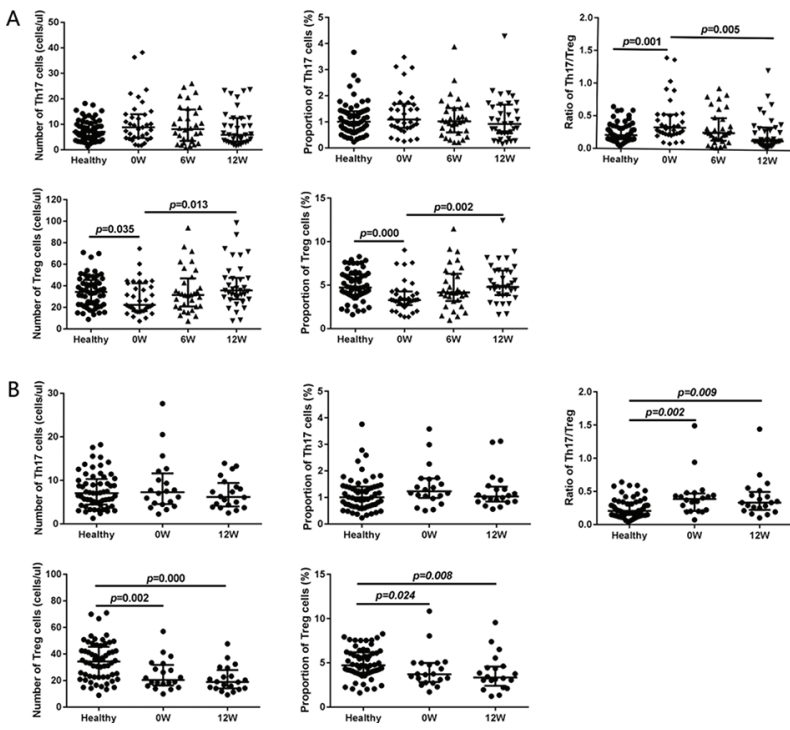

Abstract THU0184 - Figure 1. The numbers of Th17, Tregs, and the ratio of Th17/Treg in healthy controls and RA patients. A: Healthy controls and RA patients before and after sirolimus treatment. B: Healthy controls and RA patients before and after conventional treatment.

Disclosure of Interests: None declared

DOI: 10.1136/annrheumdis-2019-eular.2936

\section{THU0185 THE FIRST REPORT OF SIGNIFICANTLY IMPROVEMENT OF NT-PROBNP LEVEL IN RHEUMATOID ARTHRITIS PATIENTS TREATED WITH TOFACITINIB DURING 12- MONTH FOLLOW-UP}

Diana Novikova ${ }^{1}$, Irina Kirillova ${ }^{1}$, Eugenia Markelovaa ${ }^{1}$, Helen Udachkina ${ }^{1}$, Helen Gerasimova ${ }^{1}$, Helen Luchihina ${ }^{2}$, Dmitriy Karateev ${ }^{2}$, Natalia Demidova ${ }^{1}$, Anna Misiyuk', Maria Cherkasova', Tatiana Popkova' ${ }^{1}{ }^{1}$ V.A. Nasonova Research Institute of Rheumatology, Moscow, Russian Federation; ${ }^{2}$ Moscow Regional Research and Clinical Institute ("MONIKI"), Moscow, Russian Federation

Background: The amino-terminal fragment of the B-type natriuretic peptide prohormone (NT-proBNP) is a marker for functional cardiac impairment and is increased in heart disease with or without symptoms of congestive heart failure $(\mathrm{CHF})^{1}$.

Objectives: To prospectively investigate the effect of tofacitinib (TOFA) on the levels of NT-proBNP, as a predictor of CHF in patients (pt) with active rheumatoid arthritis (RA).

Methods: Twenty six RA pt (median age 54 [40;62] years, $81 \%$ female, disease duration $44[24 ; 63,0]$ month $(m)$, moderate to high activity (DAS28-5.1[4.6;6.1], SDAI-27(22;35)), positive for ACCP (73\%)/RF (77\%), who were non-responders to MTX at least $15 \mathrm{mg} /$ week and/or other synthetic DMARDs and bDMARDs) free of clinical overt cardiovascular disease were treated with TOFA and followed for $12 \mathrm{~m}$. TOFA therapy was started in all pt in dose $5 \mathrm{mg}$ BID per os with dose escalation to 10 mg BID in $8(31 \%)$ pt. TOFA used in combination with MTX in 24 $(92 \%)$ pt, leflunomide in 1 (4\%). Low-dose oral corticosteroids (<10 mg/ day prednisone or equivalent) were received by $9(35 \%)$ pt. Remission was achieved in 38,5\% pt (DAS28), 38,5\% (SDAI). Cardiovascular risk factors (CVRF) and the NT-proBNP levels were measured at baseline and after $12 \mathrm{~m}$. At baseline the most of pt had multiple CVRF and subclinical organ damage. Cardioprotective therapy received $16(57 \%)$ pt ( $\beta$ AB-7, ARA/ACE inhibitors-11, statins-11, dihydropyridine CCB-7). Twenty controls matched for CVRF were included for comparison of normal NTproBNP levels with those of RA pt.

Results: The NT-proBNP level was significantly higher in RA pt than in the control group (median 62.2(26.9-101.7) $\mathrm{pg} / \mathrm{mL}$ vs 44.0 (34.0-54.3) pg/ $\mathrm{mL}, \mathrm{p}<0.05)$. At baseline NT-proBNP level was higher in female than in male $(p=0,019)$. Its concentration correlated with DAS28 $(r=0,41, p=0,036)$. Three pt $(11,5 \%)$ had NT-proBNP level over $125 \mathrm{pg} / \mathrm{mL}$. All RA pt with a NT-proBNP level over $125 \mathrm{pg} / \mathrm{mL}$ were asymptomatic and exhibited normal echocardiography. Median DAS28 and SDAI were significantly reduced following TOFA treatment (from 5.1 to $2.9, \mathrm{p}<0.001$ and from 26.8 to $4.7, p<0.001$, respectively). During follow-up, no RA pt exhibited a cardiovascular event or CHF. NT-proBNP levels decreased by $63 \%$ over the 12-m of TOFA treatment (from $62.16 \mathrm{pg} / \mathrm{mL}$ to $14.8 \mathrm{pg} / \mathrm{mL}, \mathrm{p}=$ 0.011). The incidence rate of arterial hypertention (58\%vs65\%), overweight (62\%vs62\%), abdominal obesity (58\%vs62\%), smokers (27\%vs $27 \%$ ), menopausal status (52\%vs52\%), DM type 2 (7\%vs7\%), mSCORE $\geq 5 \%(23 \%$ vs27\%), subclinical carotid atherosclerosis (58\%vs58\%) did not change significantly. An increase in body mass index (BMI) was observed from $26.5[22.9 ; 29.0]$ to $26.9[24.0 ; 30.1], \mathrm{p}<0.001$ and in $\mathrm{HDL}$ level from 1.37 $[1.06 ; 1.87]$ to $1.90[1.29 ; 2.16], p<0.01$. The percentage change in the NTproBNP level significantly correlated with the percentage change in the BMI $(r=0,6, p=0,007)$, DAS $28(r=0.41, p=0.038)$ SDAl $(r=0.51, p=$ 0.009). Changes in NT-proBNP levels in RA pt with remission was greater than that observed in pt who didn't achieve remission $(-87 \%$ vs $26 \%, p=0,005)$. The percentage change in the NT-proBNP level was not correlated with the percentage change in other CVRF.

Conclusion: TOFA decreased the NT-proBNP level in patients with RA without clinical overt cardiovascular disease and CHF. TOFA may have a cardioprotective effect in those with active RA.

\section{REFERENCE:}

[1] Breunig M., Kleinert S., Lehmann S. et al. Simple screening tools predict death and cardiovascular events in patients with rheumatic disease. Scand J Rheumatol 2018;47(2):102-109. doi: 10.1080/03009742.2017.1337924.

Disclosure of Interests: Diana Novikova: None declared, Irina Kirillova: None declared, Eugenia Markelova: None declared, Helen Udachkina: None declared, Helen Gerasimova: None declared, Helen Luchihina Speakers bureau: Pfizer, Abbvie, Biocad, Dmitriy Karateev: None declared, Natalia Demidova: None declared, Anna Misiyuk: None declared, Maria Cherkasova: None declared, Tatiana Popkova: None declared DOI: 10.1136/annrheumdis-2019-eular.2865

\section{THU0186 \\ SAFETY, TOLERABILITY AND PHARMACOKINETICS OF MBS2320, A SELECTIVE MODULATOR OF IMMUNE METABOLISM, IN HEALTHY VOLUNTEERS AND PATIENTS WITH RHEUMATOID ARTHRITIS}

Lisa Patel ${ }^{1}$, Paul Marcus ${ }^{1}$, Jim Bush ${ }^{2}$, Andy Gray ${ }^{1}$, Richard Fitzgerald ${ }^{3}$,

Sonya Abraham ${ }^{4}$, Martyn Foster ${ }^{1}$, Hiep Huatan ${ }^{1}$, Laurence Skillern',

Anna Daroszewska ${ }^{5}$, Rob Van't Hof ${ }^{5}$, Sam Williams ${ }^{1} .{ }^{1}$ Istesso Ltd, London, United Kingdom; ${ }^{2}$ Covance Clinical Research Unit Ltd, Leeds, United Kingdom; ${ }^{3}$ The Royal Liverpool University Hospital, Liverpool, United Kingdom; ${ }^{4}$ Imperial College London, Faculty of Medicine, London, United Kingdom; ${ }^{5}$ University of Liverpool, Liverpool, United Kingdom

Background: Despite the availability of several treatment options some patients with Rheumatoid Arthritis (RA) fail to benefit and for those who do response rates are similar across therapeutic classes. Thus there remains a need for new therapies with novel mechanisms of action. MBS2320 is a selective modulator of immune metabolism that shows anatomically appropriate osteoid layering and a broader spectrum of osteoprotective efficacy compared to TNF $\alpha$ inhibition in preclinical models. Objectives: To investigate the safety, tolerability and pharmacokinetics of MBS2320 in healthy volunteers and patients with Rheumatoid Arthritis (RA) receiving a stable dose of methotrexate (MTX).

Methods: Cohorts of healthy volunteers (randomised 6:2 drug:placebo) received single or multiple oral doses of MBS2320 for 14 days. Single Ascending Dose (SAD) cohorts comprised 2, 10, 25, 50, 75, 125, 250 $375 \mathrm{mg}$ (PO) and Multiple Ascending Dose (MAD) cohorts 75, 100, $160 \mathrm{mg} / \mathrm{d}$. Patients with RA received $75 \mathrm{mg} / \mathrm{d}$ for 14 days in addition to their existing weekly MTX treatment. Safety and tolerability were assessed throughout. Plasma MBS2320 (SAD, MAD and patients with RA) and MTX (patients with RA only) were measured using LC-MS/MS. In patients with RA, C-reactive protein (CRP) and biomarkers of bone turnover were assessed on Day 14.

Results: A total of 96 healthy subjects and 9 patients with RA entered the Study and were randomised to the drug or matching placebo. MBS2320 was well tolerated by healthy subjects at single oral doses of 2 to $375 \mathrm{mg}$. There were no serious adverse events (SAEs). Nausea was the most commonly reported adverse event (AE) and occurred most frequently at the high doses but was mild and resolved without treatment. Daily doses of 75 to $160 \mathrm{mg}$ QD MBS2320 for 14 days were generally well tolerated by healthy subjects. The most common drug-related treatment emergent adverse events (TEAEs) were gastrointestinal disorders, 
particularly nausea. There were no significant effects on clinical laboratory tests, vital signs, ECG or physical examination.

Multiple doses of MBS2320 (75 mg) were also generally well tolerated by subjects with RA when co-administered with MTX. There were no clinically significant findings or trends in the laboratory tests, vital signs or ECG data, and no clinically significant findings on physical examination. No SAEs were reported. The majority of TEAEs were mild in severity with diarrhoea and nausea reported most frequently.

In healthy subjects, MBS2320 was steadily absorbed following doses of 50 to $375 \mathrm{mg} \mathrm{MBS2320.} \mathrm{Systemic} \mathrm{exposure} \mathrm{(AUC)} \mathrm{increased} \mathrm{in} \mathrm{a} \mathrm{dose-}$ proportional manner across all doses and was unaffected by food. In RA patients there was no indication of a PK interaction between MTX and MBS2320 in either direction.

In patients with RA, serum CTX-1, P1NP and osteocalcin increased following 14 days of treatment, while TRAP5b was decreased or unchanged. Median CRP was decreased relative to baseline in after 7 days' treatment with MBS2320, and remained low on Day 14.

Conclusion: MBS2320 was well tolerated for up to 14 days when administered to healthy volunteers and to patients with RA receiving MTX. Systemic exposure was dose-proportional with no evidence of a pharmacokinetic interaction with MTX. Evaluation of biomarkers of bone turnover and inflammation in RA patients showed changes consistent with those expected of an agent with the potential to directly protect the bone and simultaneously ameliorate inflammation.

Louise Jopling, Ian Anderson, Ian Gourley, Helen Marley and Ezi Otti Disclosure of Interests: Lisa Patel Shareholder of: Shareholder of Istesso Ltd, Employee of: Employee of Istesso, Paul Marcus Consultant for: Istesso Ltd, Jim Bush Shareholder of: Labcorp, Employee of: Covance, Andy Gray Shareholder of: Shareholder of Istesso Ltd, Consultant for: Istesso Ltd, Employee of: Astra Zeneca, Richard Fitzgerald: None declared, Sonya Abraham Shareholder of: UCB Pharma, Grant/research support from: Pfizer, Riche, Abbvie, Consultant for: Abbvie Roche Pfizer BMS UCB pharma, Eli Lilly, Employee of: UCB Pharma, Martyn Foster Shareholder of: AstraZeneca, Consultant for: Istesso, Levicept, Employee of: AstraZeneca, Hiep Huatan Consultant for: Istesso Ltd, Employee of: Pfizer, Laurence Skillern Consultant for: Istesso, Employee of: Astellas, Anna Daroszewska Consultant for: Istesso Ltd, Rob van't Hof Shareholder of: OsteoRx Ltd, Sam Williams Shareholder of: Shareholders of Istesso Ltd, Employee of: Employees of Istesso

DOI: 10.1136/annrheumdis-2019-eular.2794

\section{THU0187 EFFICIENCY OF TREATMENT SEQUENCES CONTAINING TOFACITINIB FOR RHEUMATOID ARTHRITIS IN SPAIN}

Carmen Peral ${ }^{1}$, Alejandro Balsa ${ }^{2}$, Federico Navarro ${ }^{3}$, José Luis Pablos ${ }^{4}$, Jose Manuel Martinez Sesmero ${ }^{5}$, Susana Gómez ${ }^{1}$, Monica Valderrama ${ }^{1}$, Itziar Oyagüez ${ }^{6}$, Miguel Angel Casado ${ }^{6}$, Fernando De Andres ${ }^{6}$, Maria Montoro ${ }^{1}$. ${ }^{1}$ Pfizer, Madrid, Spain; ${ }^{2}$ Hospital La Paz, Madrid, Spain; ${ }^{3}$ Hospital QuironSalud Infanta Luisa, Sevilla, Spain; ${ }^{4}$ Hospital Universitario 12 de Octubre, Madrid, Spain; ${ }^{5}$ Hospital Universitario Clínico San Carlos, Madrid, Spain; ${ }^{6}$ PORIB, Madrid, Spain

Background: The availability of oral janus kinase inhibitors, as tofacitinib, has extended the treatment pathways for management of patients with rheumatoid arthritis (RA)

Objectives: To assess the cost-effectiveness of tofacitinib as second-line treatment compared to treatment sequences containing standard biologicaltherapies in patients with moderate to severe RA after failure to diseasemodifying antirheumatic drugs (DMARDs) from the Spanish National Health System perspective.

Methods: A patient-level microsimulation model was used to compare the lifetime cost and quality-adjusted life-years (QALY) for treatment sequences initiating with tofacitinib (5mg BID) followed by biological therapies versus sequences of biological treatments excluding tofacitinib. The sequences were selected by a panel of experts based on clinical practice in Spain. Concomitant treatment with methotrexate (MTX) was considered along all the therapies in the treatment sequences.

Model parameters included age, weight, initial Health Assessment Questionnaire $(\mathrm{HAQ})$ score and clinical response to short and long treatment. Efficacy was measured by means of $\mathrm{HAQ}$ score changes using mixedtreatment-comparisons (for the first 6 months) and data from long-term extension trials (for later periods).

Serious adverse event (SAE) information derived from literature.

The estimation of total cost for sequences included: drugs acquisition (public ex-factory prices with mandatory deduction or reference prices) and parenteral administration, disease progression and SAE management.
Local unitary costs $(€, 2018)$ were applied. Additional comparisons were explored testing other potential sequences.

Results: The base case results showed that sequences initiating with tofacitinib provided greater outcomes than the correspondent sequences excluding tofacitinib. In scenario 1 tofacitinib $+M T X \rightarrow$ Rituximab+MTX $\rightarrow$ sc Tocilizumab+MTX $\rightarrow$ Etanercept + MTX $\rightarrow$ Certolizumab+MTX provided 13.99 QALYs versus 13.92 QALYs for adalimumab+MTX $\rightarrow$ Rituximab+MTX $\rightarrow$ Sc Tocilizumab+MTX $\rightarrow$ Etanercept $+\mathrm{MTX} \rightarrow$ Certolizumab+MTX. In scenario 2 tofacitinib+MTX $\rightarrow$ Adalimumab+MTX $\rightarrow$ Rituximab+MTX $\rightarrow$ sc $\quad$ Tocilizumab $+\mathrm{MTX} \rightarrow$ Etanercept+MTX provided 13.75 QALYs versus 13.62 QALYs for Baricitinib+MTX $\rightarrow$ Adalimumab + MTX $\rightarrow$ Rituximab + MTX $\rightarrow$ Sc $\quad$ Tocilizumab + MTX $\rightarrow$ Etanercept+MTX

Tofacitinib-containing sequences provided lower total costs than the alternative sequences ( $€ 5,783$ and $€ 13,975$ for the pairwise comparisons previously described), resulting, therefore, dominant options versus sequences excluding tofacitinib.

On the probabilistic sensitivity analyses, sequences initiating with tofacitinib resulted cost-effective in $64.0 \%$ (scenario 1) and $56.9 \%$ (scenario 2) of the 1,000 iterations performed, because incremental cost-effectiveness ratio fell below a $€ 25,000 / Q A L Y$ gained willingness to pay threshold.

Conclusion: These results suggest that the inclusion of tofacitinib could be a dominant strategy for treatment of moderate to severe RA patients after DMARDs failure in Spain.

Disclosure of Interests: Carmen Peral Shareholder of: Carmen Peral is employee of and shareholder in Pfizer, Employee of: Carmen Peral is employee of and shareholder in Pfizer, Alejandro Balsa Grant/research support from: Abbvie, Pfizer, Novartis, BMS, Nordic, Sanofi, Consultant for: Abbvie, Pfizer, Novartis, BMS, Nordic, Sanofi, Sandoz, Lilly, Paid instructor for: Pfizer, Speakers bureau: Pfizer, Novartis, UCB, Nordic Sanofi, Sandoz, Lilly, Federico Navarro Grant/research support from: Pfizer, Consultant for: Pfizer, José Luis Pablos: None declared, Jose Manuel Martinez Sesmero Consultant for: Pfizer, Susana Gómez Employee of: I am a current employee of Pfizer., Monica Valderrama Shareholder of: Have received shares from Pfizer, Employee of: employee in Pfizer, Itziar Oyagüez Consultant for: I am employee of PORIB a consultant company which has received financial support from Grünenthal for development of this project, Miguel Angel Casado Grant/research support from: Pfizer, Consultant for: Pfizer, Fernando De Andres Grant/research support from: Pfizer, Employee of: Pfizer, Maria Montoro Shareholder of: Maria Montoro is employee of and shareholder in Pfizer, Employee of: Maria Montoro is employee of and shareholder in Pfizer DOI: 10.1136/annrheumdis-2019-eular.6741

\section{THU0188 INHIBITION OF STRUCTURAL JOINT DAMAGE WITH UPADACITINIB AS MONOTHERAPY OR IN COMBINATION WITH METHOTREXATE IN PATIENTS WITH RHEUMATOID ARTHRITIS: 1 YEAR OUTCOMES FROM THE SELECT PHASE 3 PROGRAM}

Charles Peterfy ${ }^{1}$, Mark C. Genovese ${ }^{2}$, In-Ho Song ${ }^{3}$, Alan Friedman ${ }^{3}$

Stephen Hall ${ }^{4}$, Eduardo Mysler ${ }^{5}$, Patrick Durez ${ }^{6}$, Xenofon Baraliakos ${ }^{7}$, Jose Jeffrey Enejosa ${ }^{3}$, Tim Shaw $^{3}$, LI Yihan ${ }^{3}$, Su Chen ${ }^{3}$, Vibeke Strand ${ }^{2}$. ${ }^{1}$ Spire Sciences, Inc., Kentfield, United States of America; ${ }^{2}$ Stanford University, Palo Alto, United States of America; ${ }^{3}$ AbbVie, Inc., North Chicago, United States of America; ${ }^{4}$ Monash University, Cabrini Health and Emeritus Research, Malvern, Australia ${ }^{5}$ Organización Médica de Investigación, Buenos Aires, Argentina; ${ }^{6}$ Cliniques Universitaires Saint-Luc, Université Catholique de Louvain, Brussels, Belgium; ${ }^{7}$ Rheumazentrum Ruhrgebiet, Herne and Ruhr-University Bochum, Bochum, Germany

Background: Long-term prevention of structural joint damage is a key treatment goal in the management of $R^{1}$. Upadacitinib (UPA), a JAK1selective inhibitor, inhibited the progression of structural joint damage at 6 months as monotherapy in methotrexate (MTX)-naïve RA patients (pts) ${ }^{2}$ and in combination with MTX in pts with inadequate response (IR) to $\mathrm{MTX}^{3}$.

Objectives: To evaluate the progression of structural joint damage (radio graphic) through Week 48 in pts with moderately to severely active RA treated with UPA monotherapy or in combination with MTX.

Methods: Radiographic progression was assessed in 2 phase 3 randomized controlled trials (RCTs), as previously described ${ }^{2,3}$. MTX-naïve pts were randomized to UPA 15 or $30 \mathrm{mg}$ QD or MTX monotherapy [SELECT-EARLY, $\mathrm{N}=945$ ], while MTX-IR pts were randomized to UPA $15 \mathrm{mg}$ QD or adalimumab (ADA) $40 \mathrm{mg}$ eow or placebo (PBO), with continuous background MTX [SELECT-COMPARE, $\mathrm{N}=1629$ ]. Both RCTs specifically enrolled pts at high risk for progression of joint damage (high disease activity including elevated hsCRP, presence of baseline erosions and ACPA and/or RF positivity ${ }^{2,3}$ ). The mean changes $(\Delta)$ from baseline 